\title{
Dilemma and Breakthrough of Online Teaching Resources in Colleges and Universities under the Normalization of Epidemic Prevention and Control
}

\author{
Huaijin Liu, Junhao Feng, Yuqi Liu \\ Faculty of P. E., Hunan Institute of Science and Technology, Yueyang, China \\ Email: tyxlhj@126.com
}

How to cite this paper: Liu, H.J., Feng, J.H. and Liu, Y.Q. (2021) Dilemma and Breakthrough of Online Teaching Resources in Colleges and Universities under the Normalization of Epidemic Prevention and Control. Open Access Library Journal, 8: e8180. https://doi.org/10.4236/oalib.1108180

Received: November 11, 2021

Accepted: December 10, 2021

Published: December 13, 2021

Copyright $\odot 2021$ by author(s) and Open Access Library Inc.

This work is licensed under the Creative Commons Attribution International License (CC BY 4.0).

http://creativecommons.org/licenses/by/4.0/ (c) (i) Open Access

\begin{abstract}
Affected by the epidemic, colleges and universities have experienced one semester of online teaching and accumulated some teaching experience and resource. Under the normalization of epidemic prevention and control, offline teaching in colleges and universities has gradually returned to normal, and online teaching has become an auxiliary form of offline teaching. However, the epidemic has not ended. We still need to solve the problems of "imbalance between supply and demand" in the thinking of teaching resources design, "different functions" of operation platform, "good and bad" in construction effect, and "different standards" in quality monitoring. Aiming at the problems faced by online teaching resources in colleges and universities under the normalization of epidemic prevention and control, this paper puts forward corresponding countermeasures to improve the effect of classroom teaching and improve the quality of talent training.
\end{abstract}

\section{Subject Areas}

E-Learning and Knowledge Management, Higher Education

\section{Keywords}

Under the Normalization of Epidemic Prevention and Control, Online

Teaching Resources in Colleges and Universities, Dilemma 


\section{Introduction}

Before the outbreak of the epidemic, many colleges and universities have begun to explore online teaching. China's educational information construction has made some achievements, but it still focuses on offline teaching. On September 25, 2019, the Ministry of Education issued guidance on promoting the healthy development of online education, "by 2020, the infrastructure construction level of online education will be greatly improved, and modern information technologies such as the Internet, big data and artificial intelligence will be more widely used in the field of education; by 2022, modern information technology and education will be deeply integrated, the quality of online education will be continuously improved, a networked, digital, personalized and lifelong education system will be preliminarily constructed, and important progress will be made in the construction of a learning society" [1].

When the epidemic broke out, the whole country was in the prevention and control period of the new coronavirus. On February 4, 2020, the Ministry of Education issued the guiding opinions on doing a good job in the organization and management of online teaching in colleges and universities during the epidemic prevention and control period, delaying the opening of school in spring and blocking the spread of the epidemic to the campus. It is required to adopt the trinity of government leadership, university subject and social participation to jointly implement and ensure the online teaching of colleges and universities during the epidemic prevention and control period, so as to realize "non-stop teaching and nonstop school" [2].

Under the normalization of epidemic prevention and control, people began to think the following questions: "how to better solve the problems of online teaching during the epidemic? Do you want to continue online teaching in colleges and universities? What difficulties will exist if it continues? What is the way to solve these difficulties?" To better deal with online teaching under the new normal, on September 22, 2020, President Xi Jinping said at the Symposium of Experts in the Field of Education, Culture, Health and Sports: "we should deepen the comprehensive reform in the field of education and enhance the systematisms, integrity and synergy of educational reform." To sum up the MOOC education experience during the prevention and control of COVID-19, using information technology to update the education concept, and change education mode [3]. In this sudden epidemic, information technology played a very key role. Before the epidemic, the rapid development of information technology in China made the forms of online teaching resources diverse. It broke the traditional concept: offline teaching is the main and online teaching is the auxiliary. In the process of fighting the epidemic, colleges and universities across the country have adopted the form of online teaching, which also exposed many problems and deficiencies, especially in terms of online teaching resources. This paper puts forward corresponding solutions to the problems of online teaching resources in colleges and universities. 


\section{The Development of Online Teaching Resources in Colleges and Universities and Its Contribution in the Epidemic Prevention and Control Period}

\subsection{Development of Online Teaching Resources}

China's online teaching resources have been developing continuously in recent years. At the beginning, they are called high-quality courses: from the implementation of quality engineering by the Ministry of education in 2003 to 2010; Later, MOOC was proposed: that is, a large-scale online open course. Since 2012, this year is called the first year of MOOC. Supported by the rapid development of information technology, it is a unique course with the characteristics of "online open learning" [4]. Then there are high-quality resource sharing courses and video public courses: probably from 2014 to 2016; Then, there are high-quality online open Courses: they have been built since 2018, and the third batch is currently being reviewed at the provincial level (those in 2018 and 2019 are first approved and then recognized, and those in 2020 are directly recognized); Now the hottest topic is "golden class": the concept will appear in 2018 and the construction will begin in 2019. It includes five categories of "golden Courses", namely, online first-class courses, offline first-class courses, online and offline hybrid first-class courses, virtual simulation experiment first-class courses, social practice first-class courses, etc. [5]. These are some forms of online teaching resources, especially in this sudden epidemic, which has made a significant contribution to the normal teaching of colleges and universities.

\subsection{Contribution of Online Teaching Resources}

During the epidemic prevention and control period, most colleges and universities use online teaching, and online teaching needs the support of the platform. After the Ministry of Education issued guidance, a total of 37 curriculum platforms were recommended, and 110 platforms were successfully opened free of charge [6]. After continuous trial operation, smooth technical support can be provided for large-scale online teaching. In the teaching process, teachers will also share their own courseware to achieve resource sharing. In the teaching process, teachers can use online teaching resources to record courses or broadcast live, so that students in other schools can also watch videos simultaneously, so that students in other schools can also hear Tsinghua teachers' lessons at home.

In traditional teaching, the teacher basically only talks about the knowledge points once and may have missed it if he didn't understand it at that time, but online teaching is different. Its teaching method is more flexible, and the teaching resources can be saved. Students can watch the teacher's recording and broadcasting. It's no problem to watch it repeatedly according to their own progress, and students can clearly receive the tasks sent by the teacher After receiving the materials and information, reply in time in the group, and the teacher will know which students have received the information. After class, students can ask teach- 
ers about problems they don't know on QQ or WeChat platform. Teachers can easily reply on QQ or WeChat platform to help students solve problems. One-onone counseling is more targeted, and the effect will be better. In particular, some students are usually shy and dare not say it face-to-face. At this time, they can also send the places they don't understand or have problems in class to WeChat or QQ platform. We can discuss with each other, which greatly promotes the learning atmosphere and improves the interest of students.

\section{Practice Status of Online Teaching in Colleges and Universities during the Epidemic}

\subsection{Organization Guarantee}

In the face of this sudden epidemic, the national education department immediately made corresponding teaching measures and established an online teaching expert group. In order to ensure the smooth development of online teaching, organize teachers to carry out online teaching training and learn how to adapt to online teaching faster; how to master online instructional design accurately; How to better manage students; How to better interact and communicate with students online, and provide positive solutions to the problems encountered in the process of online teaching. For teachers, it is recommended to establish a co construction and sharing mechanism when building teaching resources, link teachers' future professional title evaluation, workload and position promotion according to the achievement contribution level and set up a series of policy incentive and guarantee mechanisms [7]. For some national, provincial and school level online highquality courses, free of charge, and for fresh college graduates facing the problem of immediate graduation, the National Education Department has also opened literature query websites such as ZHIWANG for free, which provides great convenience for college graduates to query free at home.

\subsection{Teaching Measures of Teacher Team}

During the epidemic period, teachers played a very important role and put forward high requirements for teachers, because teachers communicate directly with students. If teachers do not change from the usual offline teaching mode or copy it to online teaching, the effect will be greatly reduced. Therefore, teachers should first master the online teaching technology, do a good job in the teaching design of online teaching according to the learning characteristics of online learning students, and when online teaching is carried out on a large scale for the first time, they may encounter unexpected situations at any time, such as network jam, bad signal and other problems. Teachers should timely improve the teaching progress and teaching content according to the actual situation, it is a great challenge for teachers.

\subsection{Overall Learning Effect of Students}

Traditional offline teaching is very different from online teaching. Offline teaching 
is basically in the classroom. Teachers have classes on the podium and students listen on their seats. Online teaching breaks the limitation of space. You can carry out online learning at home or anywhere with network, and there are rich teaching resources on the network. You can carry out special modular learning according to your learning needs. You can also watch the live broadcast or recording of teachers on the Internet repeatedly according to your acceptance until you understand it, through the survey, it is found that most students are satisfied with online teaching. Among them, more than $85 \%$ of students said that during the epidemic prevention and control period, online teaching ensured their home learning and realized non-stop teaching and learning.

\subsection{Reform of Curriculum Assessment Mode}

If online teaching is carried out, a problem that must be considered is how to assess the courses learned online, play a role in detecting the learning effect of this online teaching, and bring valuable experience to better carry out online teaching in the future. The traditional offline teaching assessment method is in the form of paper. After the examination, teachers need to spend a lot of time correcting, and it is difficult for teachers to intuitively see the progress of each student's performance. Now, in the form of online assessment, teachers only need to send the electronic version of the test paper to the examination platform for assessment. The examination platform has the functions of anti-cheating and automatic correction of the test paper, which saves teachers a lot of effort. After the results come out, the system will automatically enter them into the system and make a histogram of the results of each student in the class, it is very intuitive to see the progress of each student in each assessment. And the test score is not the only basis for the final score. According to the length of online viewing learning video, question and answer, completion of after-school homework, evaluation of course teaching, etc., they are all used as the assessment content of the final score, so that the final score is objective and fairer.

\section{Dilemma Analysis of Online Teaching Resources in Colleges and Universities under the Normalization of Epidemic Prevention and Control}

\subsection{Design Thinking "Imbalance between Supply and Demand"}

Now there are many excellent courses, MOOC, golden courses and other teaching resources. Although there are many contents in it, its distribution proportion among different majors is different, and the construction of teaching resources presents "supply thinking". Some popular majors that conform to the trend and have strong teachers have high-quality and fine courses, such as, mathematics, physics, chemistry, computer courses, while some are essential in this society, still in the initial stage, emerging industries and unpopular industries, and their teaching resources are very few. People who study such majors in universities cannot get good online education [8]. Moreover, in the process of building teaching re- 
sources, teachers build what they are good at, and do not build teaching resources based on the needs of students. Many times, students are not interested in learning online teaching resources, resulting in a great discount in teaching effect. Therefore, the design thinking of many online teaching resources is "imbalance between supply and demand", the real needs of students are ignored by teachers and experts.

\section{2. "Different Functions" of Operation Platform}

The teaching platform has a great impact on online teaching. The performance of the teaching platform directly affects the effect of online teaching. The epidemic happened very suddenly. Teachers and students can only debug at home. After a little adaptation, they will go back to school soon. The school equipment is still the same as before the epidemic. If they want to continue to use online teaching under the normalization of epidemic prevention and control, they must improve technology and equipment. Among them, the problems highlighted by the online teaching platform are as follows: first, some platforms are not stable and have insufficient capacity. In the face of the successive opening of most colleges and universities, most colleges and universities will first use the online teaching method for teaching, so this will cause network congestion, video jamming, server collapse and other phenomena, Moreover, the network technology in the central and western regions lags behind that in the eastern region [9], and teachers and students will be disgusted with online teaching. The author conducted a questionnaire survey on teachers about the phenomenon of network jamming and found that $90 \%$ of teachers have been subject to different degrees of network jamming, and the teaching progress is also very difficult to control. Second, there are many teaching resource platforms, such as Chaoxing, Yuketang, Zhihuishu, China's MOOC, etc. each platform has different functions. Teachers can freely choose the teaching platform according to the characteristics, teaching tasks and contents of their own courses. Therefore, teachers of different subjects use different platforms for classes, every time students take different classes, they need to switch different platforms, which is very cumbersome. Some teachers think that to achieve better teaching results, they often need several teaching platforms to operate together. For example, the "love course" platform has many resources, but the interactive functions of teachers and students in the platform are not developed enough, Therefore, it is often necessary to use Tencent conference and other platforms for assistance. The final teaching effect may be unsatisfactory, students' attention is greatly distracted, and the learning effect is greatly discounted $[10]$.

\subsection{Construction Effect "Good and Bad"}

During the epidemic prevention and control period, although the Ministry of education has opened up more than 24,000 online high-quality course resources and provided 22 online classroom platforms for college students across the coun- 
try [11], many online teaching resources have not been carefully processed and strictly screened, resulting in the mismatch between some online courses and teaching resources, It may be that most of the courses need to be completed by teachers and experts in a very short time, which is under the pressure of a large amount of tasks and cannot ensure the high quality of the quality. Some teachers who are not very proficient in information technology are forced to embark on the road of online teaching. They may feel lucky and think that the epidemic will pass sooner or later. They will resume the offline teaching mode when the normal school starts. Therefore, they do not pay much attention to the development of online teaching resources and think that as long as the number is reached, there is no standard to judge the quality, which leads to blind construction and uploading, and there are many online teaching resources that make up for the number, low quality and nothing new. This not only leads to a great decline in students' interest in online teaching, showing insufficient enthusiasm for learning and absent-minded in class.

\section{4. "Different Standards" for Quality Monitoring}

With the continuous enhancement of China's comprehensive national strength, the mode of education is also undergoing a fundamental change, from focusing on quantity to focusing on quality. This epidemic has greatly promoted the development of online teaching resources and changed from traditional offline teaching to online teaching. After so many years of repeated practice, traditional offline teaching has become very mature, and teachers and students are also very adapted to this teaching mode. However, students' thinking is limited to a great extent, which hinders students' ability to develop creativity and self-study. This online teaching is a new exploration. In the process of online teaching, there are the following problems in teaching management and monitoring: first, it is difficult to ensure the concentration of teachers and students [12]. Online teaching does not have the collective learning atmosphere of offline teaching. It is difficult for students to immerse themselves in the teacher's passionate speech across the screen. In the process of online teaching, they can interact with the teacher by means of bullet screen and praise. On the surface, the classroom atmosphere seems very active. In fact, students may pay more attention to looking at the bullet screen frame rather than focusing on the teacher's teaching, Teachers can't well judge which students are listening carefully and which students are wandering. Moreover, teachers often look at the students' speeches on the bullet screen frame in the process of class, which will interrupt their thinking in class and reduce their concentration.

Second, the learning effect of students cannot be well supervised. In online learning, students and teachers exist in two different spaces. Offline teachers can evaluate whether students have mastered the knowledge points of the unit according to the students' response to class and the test papers. Offline teachers can judge whether students' attendance, usual grades, hits, completion and sub- 
mission of online homework can be seen on the platform, However, it is difficult to monitor the actual situation of students behind the scenes, and one learning time of students cannot be guaranteed. Therefore, the quality monitoring of online teaching is difficult to guarantee.

\subsection{Problems of Teachers and Students}

Under the normalization of epidemic prevention and control, some teachers still hope to return to the usual offline classroom and have a psychological resistance to online teaching. Secondly, some teachers' information technology ability is generally not high, and the operation is very inconvenient. If the problems such as network jam are added, they will become very helpless, and teachers will have teaching fragments in the teaching process [13], therefore, the school must take corresponding measures to adopt large-scale online teaching, such as information technology training for all teachers. Teachers' attitude and teaching ability towards online teaching is a major factor affecting the effect of online teaching.

Teachers have insufficient understanding of online teaching, lack of studentcentered teaching design, or copy the teaching mode under the front line to online teaching. The teaching effect cannot guarantee the achievement of teaching objectives. Due to the lack of face-to-face observation and communication with students in the online teaching process, in addition to paying attention to pronunciation, intonation and image in the live broadcast process, teachers should design the selection of teaching materials, the arrangement of course schedule, the setting and distribution of $\mathrm{Q} \& \mathrm{~A}$, discussion and communication links in advance. While focusing on the content of "what to teach", we should also explore and think about the problem of "how to teach". If we only upload courseware and recording and broadcasting materials and teach teaching materials without interaction, students are likely to wander and distract from classes without the supervision of teachers. Therefore, instructional design is very important for the guarantee of online teaching quality.

As for the differences in students' learner autonomy, compared with traditional offline teaching, online teaching can better reflect and expose students' ability of self-management and autonomous learning [14]. If the teaching methods designed by teachers cannot stimulate students' interest in learning, in addition, the long-time use of electronic equipment in online teaching is easy to cause visual fatigue, students' enthusiasm for class and Q \& A is not high, and they do not submit course assignments on time, will affect the effect of online teaching.

\section{Breakthrough Path of Online Teaching Resources in Colleges and Universities under the Normalization of Epidemic Prevention and Control}

\subsection{Build a Design Mode Focusing on Demand Thinking and Strengthen Collaborative Planning}

Nowadays, the construction of online teaching resources in colleges and univer- 
sities is more the teachers' own main idea, and they do not do a good job in the student-centered teaching design. Many teaching videos are published repeatedly, which makes students have no interest in learning. Therefore, when building online teaching resources, we need to do a good job in top-level design and collaborative planning. Now college students' character is very enthusiastic, cheerful and positive; secondly, they have strong curiosity and acceptance of new things; then, their thoughts are very active, avant-garde and impulsive; finally, their information technology ability is relatively strong. They are particularly interested in some popular and novel teaching methods, which are different from the previous ones. Therefore, the development of online teaching resources in colleges and universities must be carried out with the actual needs and interest of students. At the same time, the distribution of online teaching resources among different courses is unreasonable, and there are some unpopular, but there are very few online course teaching resources essential to the society. Therefore, the construction of online teaching resources should also pay attention to the majors. When building online teaching resources, we should not only pay attention to the popular majors and majors with strong foundation, Similarly, we should also pay attention to those unpopular but essential majors in the society, pay less attention to the development status, pay more attention to the majors with good development prospects, public welfare majors, etc., and less "icing on the cake" and more "help in the snow" when allocating teaching resources [8]. In this way, the imbalance between supply and demand of online teaching resources can be well solved.

\subsection{Establishment of Multimedia Digital Platform and One-Stop Integrated Online Resources}

For the construction of online teaching resources, colleges and universities should further strengthen the construction of online "golden Courses" in combination with their own actual situation, optimize the hardware facilities of information-based teaching step by step, and strengthen the construction of teaching platform [15]. First, encourage colleges and universities to give full play to their respective advantages and jointly establish high-quality online open courses to achieve resource sharing. Introduce high-quality online teaching platforms at home and abroad. At the same time, we should also develop high-quality courses, realize the sharing of high-quality online teaching resources, realize the diversity and comprehensiveness of teaching platforms, and be more conducive to students' online learning. Second, we should constantly strengthen the independent construction of our own school teaching platform, increase the cost investment, expand the capacity of the server of the online teaching platform, and the network of the teaching platform will be much more stable. Third, during the epidemic period and under the normalization of epidemic prevention and control, online teaching platforms are relatively scattered. Therefore, to solve this problem, we need to establish an online teaching information platform. Teachers and students can register their real name with one account and enter the online teach- 
ing information platform for learning, so as to avoid the problem of using different platforms for different disciplines, it is conducive to the normal development of online teaching. Students can also use the online teaching platform to preview and review offline courses, so as to realize the "one-stop" service of online and offline teaching [16].

\subsection{Establish a Multi-Level Incentive Mechanism for Online Teaching Reform}

The epidemic is very sudden. In order to actively respond to the call of the Ministry of education to suspend classes and schools, most colleges and universities have launched online teaching, so the time for teachers to prepare for online teaching is not enough. In addition, there are a large number of tasks to build online teaching resources, and some teachers who are not very proficient in information technology are forced to embark on the road of online teaching, He may have a fluke mentality and think that the epidemic will pass sooner or later. $\mathrm{He}$ will resume the offline teaching mode after the normal school starts. Therefore, he does not pay much attention to the development of online teaching resources. He believes that as long as the quantity is reached, the quality cannot be guaranteed. Therefore, the construction of online teaching resources has a great and direct relationship with the attitude of teachers [17].

First of all, we need to know whether teachers can actively participate in online teaching reform is mainly affected by three aspects. First, spiritual motivation is precisely because teachers believe that this online teaching model is only used when the epidemic occurs. After the epidemic, normal offline teaching has been restored, Therefore, I don't think it's necessary to invest a lot of energy in building online teaching resources. Therefore, the ministry of education or schools should plan to build online teaching resources for a long time, establish a new teaching evaluation system by using the Internet, and increase the evaluation content of online technology, content and teaching means. This will make teachers obviously feel that the school now attaches great importance to the construction of this online teaching resource, so they also have to work hard to achieve a cautious incentive. The second task incentive is to establish a reasonable number of online teaching resources for teachers every semester or one year and encourage teachers to cooperate with each other. New teachers use their skilled information technology ability and old teachers use their rich education and teaching ability. The cooperation between the two will achieve twice the result with half the effort. Third, material incentive. Material incentive is a more effective measure. For example, establish certain online teaching resources and give corresponding material rewards. The class hours of online teaching are also included in the workload, and the results of online teaching resources construction are added to the professional title evaluation of teachers. If these three measures are implemented at the same time, it will greatly improve the quality of online teaching resources construction. 


\subsection{Establish a Feedback Mechanism for Teaching Reform under the Mode of Online Education}

The most difficult thing for online teaching is the monitoring of teaching. Like offline teaching, teachers can truly and effectively reflect the mastery of students' learning knowledge according to the answers in class, the exams after class and the correction of homework. In online teaching, it is difficult for students and teachers to truly understand students' learning through the screen, and the teaching management system of most colleges and universities remains the same as before the epidemic, without establishing a good online teaching feedback mechanism, which is also a key factor affecting whether teachers can actively participate in the reform of online teaching resources. Therefore, In order to better promote the reform of online education, Internet technology should participate and establish a "Trinity" feedback mechanism of school, teacher and student, as shown in Figure 1.

Firstly, we establish a feedback mechanism between teachers and schools, so that schools can accurately and effectively understand whether teachers are carrying out online teaching reform and establish a supervision system and teaching quality evaluation system suitable for online teaching mode. The teaching platform has powerful storage and recording functions, which can record teachers' daily teaching and students' daily learning. The school enters the platform to check, guide and check from the aspects of curriculum teaching design, teacher-student interaction, rational use of teaching resources, assessment process, etc. [18], and provide some technical support on teaching. The school shall arrange relevant personnel such as counselors and head teachers to participate in online lectures every day, timely record the notes of lectures, and master the online teaching and lectures of teachers and students in real time, so that the problems of teachers and students can be solved in time.

Secondly, we should establish an information feedback mechanism between students and schools. Once a week or every month, teachers should send the feedback form of online teaching to the students in the class. After collection, they should uniformly submit it to the school information center for statistics and analysis and modify the teaching management mode according to these feedback forms. In addition, through online lectures, the supervised teachers see

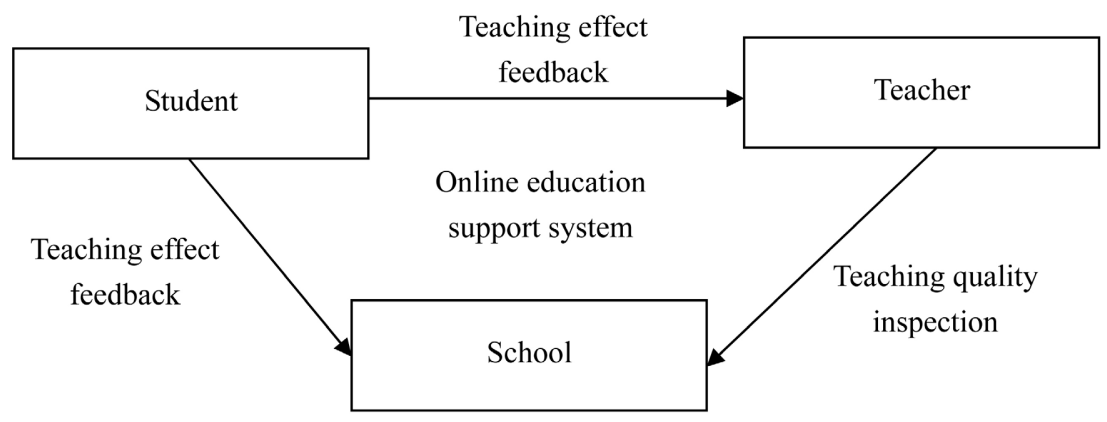

Figure 1. School-teacher-student “Trinity” feedback mechanism. 
the information on the barrage and the information in the discussion area, collect the information, and finally feed it back to the school's information collection center.

Finally, teachers should establish a feedback mechanism with students. Teachers' collection of students' feedbacks is conducive to improving teachers' investment in teaching reform, because it will have a sense of satisfaction and achievement for teachers' teaching, which is also the most attractive charm of the teacher industry. From the survey results of most colleges and universities, it is difficult for students to concentrate on learning online, and they are vulnerable to the impact of the environment. Therefore, we need to establish a feedback mechanism for the effect of online teaching and communicate with college students in the process of online teaching, which not only greatly improves students' academic performance, but also greatly improves teachers' sense of achievement and satisfaction, so as to promote the reform of online teaching methods. Although the way of online teaching prevents teachers and students from face-toface contact, we can make full use of Internet technology and obtain more teaching feedback than offline teaching. For example, we can see students' learning time, homework completion, participation in classroom discussion, etc. on the platform [19], which aspect is not good, Teachers can correspondingly modify the teaching plan and homework arrangement. In online teaching, students can also watch the playback. If they find problems they don't understand in the previous live class, they can return to the corresponding place again and listen again and again until they understand. If they still don't understand problems by themselves, they can send them to QQ group or WeChat group to ask students or teachers, so as to create a good learning environment, let students actively participate in learning, so that sub teachers can get timely feedback, improve teachers' enthusiasm in class, and students can learn more efficiently.

\subsection{Teachers Improve Information-Based Teaching Ability and Students Change Their Ideas}

Under the normalization of epidemic prevention and control, teachers should establish the awareness of online and offline mixed teaching, continue to apply the online teaching ability and experience learned during the epidemic, and constantly learn new information technology to improve their information-based teaching ability. Teachers should continue the construction of online teaching resources, enrich the teaching resource database and create a hybrid "golden class". When designing teaching, we should take students as the center and students as the starting point [20]. In the process of practice, we should constantly improve the teaching scheme, and pay attention to the flexible form of teaching organization, such as design teaching, development teaching, individual teaching, etc., so that the combination of online and offline teaching will achieve better teaching results.

After the epidemic, students' learning methods have also changed. In order to better adapt to online learning methods, students should change their previous 
ideas. In the past, they only had to sit and listen to the teacher and interact face-toface with the teacher in class. Online teaching will have more novel forms of interaction with teachers, so that students' participation in the classroom will be higher. Moreover, online teaching can learn anytime and anywhere, free from the constraints of classroom time and venue, which is more in line with the way of post-95 learning, so as to achieve the deep integration of teaching and learning.

\section{Conclusion}

Research on problems and countermeasures faced by online teaching resources in colleges and universities under the normalization of epidemic prevention and control provides theoretical guidance and survey data for this paper. Research on the theoretical framework and practical path of the construction of online provides a theoretical model and practical verification. Online teaching is a new teaching method that emphasizes the subject status of students and reflects teachers' guiding ability [21]. This teaching method has changed teachers' teaching methods, stimulated students' interest in acquiring knowledge and improved students' self-study ability. In this special period of national unity to prevent and control the epidemic, we should pay attention to the teaching reform of online education as well as overall planning and resource sharing, and we shouldn't discard the various experiences accumulated during the epidemic. College teachers should constantly strengthen their own information-based teaching literacy to improve the construction quality and application effect of "Golden Courses" [22]. To further strengthen the reform of online and offline hybrid courses and build more courses into "Golden Courses" of hybrid teaching, schools need to strengthen institutional and technical support and improve teachers' and students' information literacy; We need to pay attention to problems such as weak supervision, slow improvement in skill and the lack of emotional communication. Schools, teachers and students should make joint efforts and debugging to adapt to the new normal of online teaching, so that teaching can be organized smoothly and achieve good results. Only by maintaining a stable network platform, using and creating high-quality teaching resources, designing suitable online teaching methods, and effective organizing and implementing online teaching, can we quickly improve the effect of online teaching and ensure the quality of online teaching.

\section{Acknowledgements}

This study was sponsored by the key research projects of Hunan Social Science Achievement Evaluation Committee "Research on Problems and Countermeasures Faced by Online Teaching Resources in Colleges and Universities under the Normalization of Epidemic Prevention and Control" (XSP21ZDI006) in 2021, and the "13th Five-Year Plan" of Hunan Educational Science "Research on the Theoretical Framework and Practical Path of the Construction of Online" Golden Courses in "Physical Education in Colleges and Universities" (XJK20BTW002). In 
2020, the research project on teaching reform of colleges and universities in $\mathrm{Hu}-$ nan Province "Research and Practice on Promoting Online Teaching Resource Sharing of College Physical Education Based on OMO” (HNJG-2021-0767) in 2021, and the research and reform practice project on new liberal arts of Hunan Institute of Science and Technology "innovation and practice of teaching methods of college physical education teachers integrating modern information technology" (Hu Li Gong Zheng Tong [2021] No. 14: p. 11) in 2021.

\section{Conflicts of Interest}

The authors declare no conflicts of interest.

\section{References}

[1] Eleven Departments including the Ministry of Education in China (2019) Guidance on Promoting the Healthy Development of Online Education. http://www.moe.gov.cn/srcsite/A03/moe 1892/moe 630/201909/t20190930 401825 $\underline{\text { html }}$

[2] The Ministry of Education in China (2020) Guidance on the Organization and Management of Online Teaching in Colleges and Universities during Epidemic Prevention and Control. http://www.moe.gov.cn/jyb xwfb/gzdt gzdt/s5987/202002/t20200205 418131.html

[3] The Ministry of Education in China (2019) Implementation Opinions of the Ministry of Education on the Construction of First-Class Undergraduate Courses. http://www.moe.gov.cn/srcsite/A08/s7056/201910/t20191031 406269.html

[4] Zhang, C., Xu, X.F., Chu, D.H., Ji, Z.Z. and Gu, S.L. (2020) Building MOOC with Chinese Characteristics and Promoting Teaching Quality Improvement and Upgrading-Review, Model, Application and Thinking. Higher Science Education, 6, 46-61.

[5] Qin, J. (2019) Technology Driven Learning to Create a Foreign Language "Golden Course"-Research on the Current Situation, Problems and Countermeasures of the Construction of High-Quality Online Open Courses in Foreign Language Countries. Foreign Language Audio-Visual Teaching, 3, 55-61.

[6] Zhu, Y.H., Gong, Y.Q. and Xu, Y.Y. (2020) Overall Promotion Path of Normalized Application of Online Education in Primary and Secondary Schools in the Post Epidemic Era-Based on the Experience of K-12 Online Education in the United States. Modern Educational Technology, 11, 120-126.

[7] Chen, L. (2012) Development Strategy and Path Choice of Educational Informatization in Chinese Colleges and Universities. Educational Research, 4, 50-56.

[8] Yang, L. and Jiang, K. (2020) Current Situation, Problems and Reflection on Online Teaching in Higher Vocational Colleges during Epidemic Prevention and Control. Education and Occupation, 13, 99-103.

[9] Guo, Y.X., Li, G.P. and Chen, W.Y. (2020) Regional Differences in Large-Scale Online Teaching in Colleges and Universities in China-An Empirical Study Based on the Questionnaire of Teachers and Students during the Epidemic. Research on Educational Development, 11, 37-48.

[10] Huang, T.L., Wang, J.P., Liang, H., Shi, W.X., Li, W.G. and Lu, J.H. (2020) Exploration and Practice of Online Teaching in the Background of New Crown Pneumonia Epidemic Situation and Reform Thinking-Taking Water Supply and Drainage Science and Engineering Teaching in Universities for Example. Water Supply and 
Drainage, 9, 149-155.

[11] Wei, S. (2020) Exploration on the Informatization Construction of Higher Education Law Courses under the Epidemic Situation. Heilongjiang Higher Education Research, 11, 148-152.

[12] Lrii, Q.L. and Bu, Y.L. (2020) Analysis and Countermeasures of Online Teaching Application in Higher Vocational Colleges during the Epidemic Period-Taking Shandong College of Traditional Chinese Medicine as an Example. Vocational and Technical Education, 26, 50-53.

[13] Hu, X.P. and Xie, Z.X. (2020) Analysis on the Advantages and Challenges of Online Teaching in Colleges and Universities under the Epidemic. China Higher Education Research, 4, 18-22 + 58 .

[14] Liang, L.M. and Xia, Y.Y. (2016) Online Education in American Colleges and Universities: Current Situation, Obstacles, Motivation and Enlightenment-An Analysis Based on the Twelve-Year Survey Report of Sloan Alliance. Open Education Research, 1, 27-36.

[15] Lv, T.T. and Wang, N. (2016) Research on Flipped Classroom Teaching Model Based on SPOC + Digital Teaching Resource Platform-Taking College English as an Example. China Audio Visual Education, 5, 85-90 + 131.

[16] Zhang, Y. and Cao, Y. (2017) Diversified Co Construction and Sharing of Digital Teaching Resources under the Background of Big Data. Jiangsu Higher Education, 11, 71-73.

[17] Jiang, H.F., Liu, Y.P. and Zhang, B. (2021) Research on Behavior Choice, Motivation and Countermeasures of College Teaching Reform under the Mode of Online Education. Heilongjiang Higher Education Research, 1, 150-155.

[18] Zhong, B.L. and Fang, F. (2016) Teaching Reform in the Context of "Internet plus". Education and Occupation, 19, 5-7.

[19] Zeng, L.W. (2020) Analysis on the Implementation Effect and Influencing Factors of Offline Teaching in the Context of Epidemic Prevention and Control-Based on the Survey of Colleges and Universities in Guangdong Province. Exploration of Higher Education, 7, 85-91.

[20] Xie, Y.R., Qiu, Y., Huang, Y.L. and Wang, Q.L. (2020) Characteristics, Problems and Innovation of "No School Suspension" Online Teaching Method during Epidemic Prevention and Control. Audio Visual Education Research, 3, 20-28.

[21] Liu, H.J., Liu, Y.Q. and Feng, J.H. (2021) The Realistic Dilemma and Breakthrough Ways of Improving the Quality of Online Teaching Resources of Physical Education in Colleges and Universities. Advances in Physical Education, 11, 1-11. https://doi.org/10.4236/ape.2021.111001

[22] Liu, H.J. (2021) Research on the Cultivation of Information Teaching Literacy of College Physical Education Teachers under the Background of "Golden Course" Construction. Contemporary Physical Education, 40, 17-18. 